\title{
Lexis
}

Journal in English Lexicology

$10 \mid 2017$

The Expression of Intensity

\section{From vogue words to lexicalized intensifying words: the renewal and recycling of intensifiers in English. A case-study of very, really, so and totally}

Lucile Bordet

\section{(2) OpenEdition \\ Journals}

Electronic version

URL: http://journals.openedition.org/lexis/1125

DOI: $10.4000 /$ lexis. 1125

ISSN: 1951-6215

Publisher

Université Jean Moulin - Lyon 3

\section{Electronic reference}

Lucile Bordet, «From vogue words to lexicalized intensifying words: the renewal and recycling of intensifiers in English. A case-study of very, really, so and totally », Lexis [Online], 10 | 2017, Online since 30 September 2017, connection on 19 April 2019. URL : http://journals.openedition.org/lexis/1125 DOI : 10.4000/lexis. 1125

This text was automatically generated on 19 April 2019

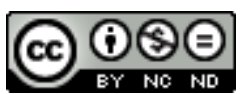

Lexis is licensed under a Creative Commons Attribution-NonCommercial-NoDerivatives 4.0 International License. 


\title{
From vogue words to lexicalized intensifying words: the renewal and recycling of intensifiers in English. A case-study of very, really, so and totally
}

\author{
Lucile Bordet
}

\section{Introduction}

1 The purpose of this paper is to investigate the renewal of intensifiers in English over time and the consequences of such a renewal process. Building on Partington [1993], Tagliamonte [2007], Tagliamonte \& D'Arcy [2007], Rissanen [2008], Mendez-Naya [2008] and Bordet [2014] and [2015], it is assumed that intensifiers are popularised because of their intensifying force. According to Bussman [1996: 22] or Herwig [1998], those adverbs that are selected to become intensifiers generally belong to the subcategory of adverbs of manner. Through frequency of use and over time, intensifiers tend to lose their intensifying force. That is when the renewal process occurs. This process promotes other adverbs, be they newly created adverbs or already existing ones, to the rank of intensifiers. Some adverbs of manner therefore take on new functions and develop new uses and senses in contexts in which they would not naturally occur. Occasionally, a newly created intensifier may become the most frequently-used one until it loses its intensifying force and needs to be replaced again by other more expressive forms.

2 The renewal process that I have just described does not merely concern the replacement of once-popular adverbs by newer, fresher ones. It also seems to impact on language register through a recycling process of existing intensifiers. Indeed, 'older' intensifiers are not entirely replaced by newer, more expressive intensifiers as one might think at 
first glance. 'Older' intensifiers remain in use, but they are assigned new functions and they are employed in different contexts.

3 My assumption is that intensifiers that have recently emerged such as totally tend to bear on adjectives or other parts of speech belonging to colloquial language, and as such they tend to be used by younger speakers or at least by speakers who want to appear young to the hearer. Indeed, many studies have shown that intensifiers tend to be popularized mostly by the young. (See Bauer \& Bauer [2002]; Paradis \& Bergmark [2003]; Tagliamonte \& D'Arcy [2007]). On the contrary, adverbs that developed into intensifiers a long time ago such as very tend to modify adjectives or other parts of speech belonging mostly to the standard or formal registers. I therefore posit a correlation between the intensifying force of an adverb and language register.

4 The first part of this paper will deal with the causes of the renewal process. I will briefly present those intensifiers that were most frequently used at some point in their development. The second part of this paper will be devoted to the presentation of the corpus I used for my study. Finally, in the last part, I will analyze the uses of the four most frequently used intensifiers of the $21^{\text {st }}$ century while attempting to show that there is a correlation between the register and the intensifier that is used.

\section{The renewal of intensifiers}

5 Intensifying adverbs generally derive from adverbs of manner and are most likely to belong to the semantic fields of quantity and size, reality and unreality, fright and disgust, power and violence, value and truth, mental diseases, uniqueness and upper and outer location (see Lorenz [1999] and [2002], Claudi [2006] and Bordet [2014] and [2015]). It is worth noting that all these semantic categories refer to more or less 'intense' extralinguistic notions and/or the high - sometimes absolute - degree of a property. All four adverbs under scrutiny may be linked to the semantic fields mentioned above.

It has been established that intensifiers emerge thanks to their high intensifying potential, which can lead to an increased frequency of use (see Lorenz [1999] and [2002], Claudi [2006] and Bordet [2014] and [2015]). Yet, almost as soon as a given intensifier has gained popularity due to its intensifying force, the said intensifying force begins to decline because it is perceived as less expressive. Therefore a suitable adverb needs to be found to replace the intensifier that was the most frequently used. Another explanation could reside in the fact that intensifiers are popularized by young speakers who experiment with language to find the latest trendy expressions, which contributes to the feeling of being part of a group, a phenomenon also known as 'ingroupness'. With the rise of its frequency of use, a given adverb will be used by a wider range of speakers and not only by younger speakers. As a consequence, they can no longer be used by a specific group, i.e. young speakers. This results in a loss of trendiness and appeal for the young who will search for another more expressive word to use within their group until it becomes popular and spreads again to other groups of speakers. Following Pinker's "euphemism treadmill" [2008], I chose to name this phenomenon the "intensification treadmill', which leads all popular intensifiers to be replaced by other adverbs and to be recycled for other purposes. In other words, the most popular intensifiers originated as vogue words that experienced such popularity that they became lexicalized as intensifying adverbs before losing their intensity and their appeal so that they had to be renewed. 
Before going any further, it may be necessary to explain why I consider that intensifiers have undergone a lexicalization process insofar as they are mostly existing adverbs that develop into intensifiers.

If the current most common intensifiers were not initially used as intensifying words but as mere adverbs of manner, I posit that, as they started to be used as intensifiers, the meaning of those adverbs of manner expanded so they could be used in contexts in which they would not normally occur. As they gained in popularity, they began to be resorted to more and more frequently and their newly developed intensifying value was adopted into the lexicon. Indeed, the Merriam Webster Unabridged Dictionary [2014] corroborates this theoretical stance, for the dictionary displays two distinct entries for each adverb of manner that has developed into an intensifier: one devoted to its use as an adverb of manner and one devoted to its use as an intensifier. As such, I argue that the intensifying value of an already existing adverb of manner may be considered as the result of a lexicalization process, the term 'lexicalization' being used in its broadest sense, i.e. adoption into the lexicon. ${ }^{1}$

Mustanoja [1960] retraces the evolution of the renewal of the most frequently-used intensifiers from the $14^{\text {th }}$ century to the $20^{\text {th }}$ century. I reproduce the chronology he established below:

- $13^{\text {th }}$ century: well

- $14^{\text {th }}$ century: full

- $15^{\text {th }}$ century: right

- $16^{\text {th }}$ century: pretty

- From the $16^{\text {th }}$ century to the $19^{\text {th }}$ century: very

- $20^{\text {th }}$ century: really

The study I have conducted gives insight into the most frequently-used intensifiers of the $21^{\text {st }}$ century. Indeed, if really was still the most frequently used intensifier at the beginning of the century, it was quickly replaced by so (Bordet [2014] and [2015]; Tagliamonte \& Roberts [2005]), which itself might be replaced by totally in the foreseeable future.

11 This particular study will focus on the four most frequently-used intensifiers of the $21^{\text {st }}$ century, i.e. very, really, so and totally, with occasional references to other formerly frequent intensifiers to illustrate my point when attempting to highlight the correlation between the renewal of intensifiers and the variations in register.

\section{Presentation of the corpus and method used}

Before I explain the results I obtained from the data I analyzed, I shall introduce the corpus from which I extracted the data for the present study. I based my work on all 9 seasons of the American TV series How I Met Your Mother (henceforth HIMYM). The conclusions drawn at the end of this paper will therefore apply to American English. Further studies using appropriate data would be necessary to determine if the same conclusions could be applied to other varieties of English.

13 I chose this TV series as source material for several reasons. Firstly, HIMYM displays remarkable longevity totalling 9 seasons over 9 years, which is quite rare for a TV series. Choosing this particular sitcom ensured enough source material to obtain relevant and coherent data. Secondly, the characters are all between the age of 20 and $40 .{ }^{2}$ Since 
intensifying words are generally used and created by young people (Tagliamonte \& Roberts [2005]), I expect to find data confirming this hypothesis. The fact that the series ran for 9 years should also be an indicator of any evolution in the use of intensifiers, be it the replacement of a frequently-used intensifier by a more expressive adverb, the rise of a newly created one, or a variation in the use of intensifiers as the characters grow older. Thirdly, sitcoms have an oral and humorous nature. Indeed, intensifying words are mostly used in spoken discourse (Tagliamonte \& Roberts [2005]) and conveying humor is one of their several functions (Bordet [2014]). Let us also note that intensifiers are firstly created orally before being used in written speech - if they are at all. As Brinton [1996: 33] states, speakers tend to display more subjectivity in spoken discourse. Bordet [2014] and [2015] as well as Xiao \& Tao [2007: 241] have shown that one of the defining characteristics of intensification was subjectivity. As a consequence, I believe that this kind of media is particularly relevant for the study of intensification.

While it may be argued that the source material is fictional English, Tagliamonte \& Roberts [2005: 280] explain that they conducted similar studies on both authentic and fictional corpora belonging to the sitcom genre (Friends) and the results they obtained were highly similar:

The Friends data exhibit almost the same overall rate of intensification as similar studies of contemporary English, and the same intensifiers occur most frequently: really, very and so. [...] Moreover, in Friends the once primary intensifier, really, is being usurped by so [...]. Taken together, these findings support the claim that media language does reflect what is going on in language and may even pave the way for innovation. ${ }^{3}$

Building on their study on the TV series Friends, which aimed to show that really was the most frequently used intensifier, my aim is twofold: I intend to investigate the renewal of intensifiers and confirm the assumption that really has already been replaced by another intensifier in terms of frequency of use.

Even if the present study will only deal with a restricted number of intensifiers, i.e. those that are most frequently used in contemporary American English, there is a wide variety of intensifying devices at work in English (see Bordet [2014]; Bordet \& Jamet [2015]), most of which cannot be processed automatically by using software. Even the adverbs commonly used as intensifiers can take on several functions such as adjunct of manner or discourse marker. It was only after a close scrutiny of the context that I was able to classify them under one category. Therefore I had to sort through the data manually and decide whether adverbs such as really or so were used as intensifiers or as mere discourse markers, which is a function that they developed after being frequently used as intensifiers $^{4}$. I analyzed 208 episodes of 22 minutes each, which amounts to approximately 80 hours of recorded speech material and 678,794 words ${ }^{5}$.

\section{A closer look at the four most popular intensifiers of the $21^{\text {st }}$ century: very, really, so and totally}

18 The table below shows the number of times the adverbs under scrutiny occur in each season: 
Table 1: Number of occurrences found in the corpus

\begin{tabular}{|l|l|l|l|l|}
\hline & Very & Really & So & Totally \\
\hline Season 1 & 39 & 101 & 144 & 60 \\
\hline Season 2 & 44 & 141 & 156 & 54 \\
\hline Season 3 & 42 & 130 & 125 & 48 \\
\hline Season 4 & 42 & 142 & 123 & 33 \\
\hline Season 5 & 47 & 138 & 168 & 36 \\
\hline Season 6 & 32 & 154 & 140 & 41 \\
\hline Season 7 & 25 & 151 & 149 & 30 \\
\hline Season 8 & 37 & 127 & 123 & 35 \\
\hline Season 9 & 44 & 142 & 150 & 43 \\
\hline Total & $\mathbf{3 5 2}$ & $\mathbf{1 2 2 6}$ & $\mathbf{1 2 7 8}$ & $\mathbf{3 8 0}$ \\
\hline
\end{tabular}

Even if there is a difference of only 52 occurrences, as Tagliamonte \& Roberts [2005] had predicted, the frequency of use of so is now higher than that of really, which makes so the most frequently-used intensifier of this century. Really is therefore relegated to the second position, which makes it the second most frequently-used intensifier. Totally ranks at number 3 and seems to be on the rise ${ }^{6}$. It may be a potential candidate for the replacement of so if its use continues to expand. Very has the fourth highest frequency of use, but it is not as high as the frequency of use of the adverb so.

As adverbs, intensifiers are typically used to modify adjectives, but they may also be used to modify other parts of speech such as other adverbs or verbs. In a different study (Bordet [2014]), I showed that intensifiers are subject to a grammaticalization process. The less grammaticalized items tend to be used rather freely while the most grammaticalized intensifiers exhibit restrictions and constraints in syntactic mobility. They also tend to occur in a wide variety of contexts before undergoing restrictions in their distributional patterns as I shall explain in the following subsections devoted to each adverb under scrutiny.

\subsection{Very}

In the corpus I used for this study, very and the other adverbs I intended to analyze tend to be used mostly with adjectives expressing opinion or appreciation. They convey the speaker's opinion and subjectivity. Let us note that very in particular has reached an advanced stage of grammaticalization and lexicalization. As such, it may be seen as a function word as Bolinger [1972: 28] confirms: "[i]f there are function words, very is surely one of them". Some scholars, such as Stoffel [1901: 33], go as far as saying that very is an empty word: 
It is easy to see that a word which at so early a period was on its way to become an

"empty" word, was especially adapted for being used as a colourless intensive. hypothesis that it may be retrieved in all its uses, maybe not in its literal sense but certainly on the metadiscursive level. While very has apparently lost the most part of its semantic contents through the grammaticalization process, it has gained some functional properties as well as the intensifying potential proper to intensifying words, even if the high frequency of use led its intensifying force to wane over time, which itself paved the way for the rise of really, whose intensifying force was perceived as stronger. That is why very is now merely used to refer to 'high degree' and not to 'very or extremely' high degree $^{7}$ which would require the use of more expressive and more intense adverbs as the following examples taken from the corpus tend to confirm:

(1) Lily: The brides are very stressed before a wedding. Well, of course, I was under control. HIMYM S04E05

(2) Ted: No, no, no, it's just... Well, you're married and we've been drinking and I was worried we might... This is a very bad idea. HIMYM S03E12

(3) Holly: I loved that he called me right away. It's very romantic. HIMYM S04E21

In these examples, the notion of truth may not be obvious as first glance. However, I posit that notion of truth is still attached to each occurrence of very insofar as it may be retrieved on the metadiscursive level as the following gloss of example (1) shows: The brides experience a high level of stress and I assure you that this statement is true. Such a gloss was always possible with all the occurrences of very I analyzed. The concept of 'hiding-highlighting' borrowed from cognitive linguistics may be useful to explain the phenomenon at work in the use of intensifiers. Indeed, I put forward that all uses of very carry two interpretations and that the original meaning may be retrieved but has shifted to the metadiscursive level and is therefore less perceivable at first glance (hiding), while the intensifying force is prevalent (highlighting).

As far as intensity is concerned, all three examples display a high degree of the quality expressed by the adjective that is modified by the adverb. However, a higher degree could be expressed if another, more intense, adverb was to replace very, as the following examples illustrate:

(1') Lily: The brides are really / so / totally stressed before a wedding. Well, of course, I was under control.

(2') Ted: No, no, no, it's just... Well, you're married and we've been drinking and I was worried we might... This is a really bad idea. 
(3') Holly: I loved that he called me right away. It's really / so / totally romantic.

\begin{abstract}
that very is not an 'empty' word devoid of all meaning. It has merely lost part of its intensifying potential and is now restricted to the expression of moderately high intensity, which would correspond to what Quirk et al. [1973] name boosters, whereas so or totally would fall under the category of maximizers according to their classification.
\end{abstract}

\title{
3.2. Really
}

As the second most frequent intensifier in contemporary American English, numerous occurrences of really are to be found in my corpus. Since it is a relatively recent intensifier, it is assumed that the use of really should be relatively constraint-free and that it should occur in a wide variety of contexts. The corpus analysis confirms this hypothesis as really is found to occur in front or medial positions, modifying adjectives, adverbs, verbs, prepositional groups, whole propositions as well as the discourse itself in some cases. The fact that really is so widespread is a sign of relatively advanced grammaticalization which may result in increased constraints and loss of semantic contents if the grammaticalization process keeps running its course.

According to Defour [2012], the use of really as an intensifier derives from the adverb of manner and dates back to the $16^{\text {th }}$ century. From an adverb which originally referred to actual facts perceptible in the extralinguistic world, really evolved to denote a high degree of reality (and by extension a high degree of truth) and developed metadiscursive uses, just like very, as the following examples illustrate:

(4) Barney: I know Robin was never really married. HIMYM S02E09

(5) Charity: Why don't you recite your favorite passage of scripture?

Ted: That's a great idea, Charity. But, really, I don't know. I mean how do you

choose your favorite passage? It's the Bible; there's so many... great ones...

That one from Pulp Fiction's pretty cool. HIMYM S02E11

In (4), really may be replaced by actually because it expresses a certain degree of reality, whereas in (5), really may be interpreted as a metadiscursive comment even if both interpretations may coexist.

As far as its intensifying force is concerned, Loewenberg [1982] wrote that really was a "signal for hyperbole", which suggests that in the 1980's, really had retained all of its expressive potential. Later, Labov [1984] noted that really was "one of the most frequent markers of intensity in colloquial conversation", thus signaling an increase in its uses and highlighting that it belonged to the colloquial register. I shall come back to this point in the last subsection of this paper devoted to the issue of variation in register depending on which intensifier is resorted to.

Following Tagliamonte \& Roberts [2005] really has replaced very historically in terms of frequency and intensity. It is therefore assumed that really has kept a higher intensifying force than very, even if it has itself been recently replaced by so (see following subsection). The following examples extracted from the corpus confirm this hypothesis:

(6) Barney: Hey, guys, what up?

Robin: Barney, where have you been?

Ted: Yeah, we're-we're really sorry about that.

Lexis, $10 \mid 2017$ 
Lily: Yeah, so sorry. But seriously, what was up with the tape? No, no, stay. HIMYM S01E15

(7) Robin: I had a really great time tonight. HIMYM S01E01

In (6), really is used to modify the adjective sorry. It may very well be substituted by very (We're very sorry about that) but Ted's being sorry would be lessened because the intensifying force of very is not felt as strong as that of really from a semantic point of view. Indeed, the speaker resorts to really to make his apology sound more heartfelt to show the depth of how sorry he feels. As Benzinger [1971] and later Burridge \& Bergs [2016] state, 'humans are natural born exaggerators and hyperbole is a major driving force behind semantic change'. The reasons for exaggerating may range from the need to convey one's emotions as accurately as possible, the need for catharsis, the desire to be understood or to be humorous, to the need to convey a specific ethos of oneself.

Interestingly, Lily's line also expresses an apology but she uses so which has an even stronger intensifying force than really, as if to insist on how sorry they both are, which could not have been conveyed by the mere use of very. In (7), really modifies the adjective great. Using very in this context would sound unnatural (??I had a very great time) ${ }^{8}$ most likely because of the semantics of great, which in itself refers to a rather intense quality. There are plenty of other similar examples in the corpus. Therefore, it seems to suggest that intensifiers are subjected to semantic constraints. Indeed, a given intensifier may only be used to modify an element that refers to a notion or a quality of lesser or equal intensity. Provided that the function of intensifiers is to boost or enhance a notion or a quality, it is only logical that the semantic contents of an intensifier should refer to more 'intense' notions or qualities than the element it is supposed to modify.

On a scale of intensity going from the lowest degree to the highest degree, really thus seems to be placed higher up than very without reaching the highest point - totally would be used for that purpose. Really, just like very, would therefore belong to the class of boosters according to Quirk et al. But the main semantic difference between the two intensifiers lies in the fact that really is used to express a type of intensity that is slightly stronger than that expressed by very.

\subsection{So}

As I have pointed out, both the frequency of use and the intensifying force of really have already begun to decline. The direct consequence lies in the emergence of so as the most frequent intensifier of the $21^{\text {st }}$ century. If really was deemed "colloquial" by Labov [1987], this is all the more true of so, which is often used by younger speakers.

So derives from old English swa which either meant 'in this way', or 'to that extent'. Just like all the other adverbs that became intensifiers, the first uses of so expressed manner. According to Tagliamonte \& Roberts [2005: 369], the first attested instance of so used as an intensifier dates back to $1837 .{ }^{9}$

Since the use of so as an intensifier is relatively recent compared to the other intensifying adverbs I have discussed, it should exhibit few syntactic constraints and it should be found in a wide variety of distributional contexts. According to Bulgin et al. [2008], so cannot modify attributive adjectives. ${ }^{10}$ It can only modify predicative adjectives and other parts of speech. As for the semantic constraints, Bulgin et al. report that there are none, which can be explained by the fact that, unlike very, so is used to express a very high degree of intensity. 

colloquial by some dictionaries such as The Merriam-Webster Dictionary of English Usage [1994] or the Random House Unabridged Dictionary [2005]. For Tagliamonte [2007], resorting to so as an intensifier is "trendy": "[T]he television scenario in which the actors are performing champions a trendy expressive style." This is in keeping with the relatively recent development of so as a popular intensifier and the penchant of the young for trendiness.

As for the intensifying potential of so, it generally denotes a higher degree than very or really do, as the following examples illustrate:

(8) Girl: I am so drunk. When I'm this drunk, I go crazy! HIMYM S01E18

(9) Lily: Baby, baby, I was so worried about you. Why didn't you call me? Marshall: I tried, baby. All the circuits were jammed. But wait, there's more. After party number four, I figured you guys went to party number five. And so I went there, too, and it is awesome. I want to cry, it is so awesome. We have to go there. HIMYM S01E11

In (8), so expresses a high degree of drunkenness. Let us underline the presence of this used to modify drunk in the following utterance. Consequently, if it is theoretically possible to use very or really to modify drunk, it would not be adequate in this particular context because neither would convey the idea of a sufficiently high degree of intensity. In (9), Marshall tells Lily that he has been to an "awesome party". In this case, the semantic contents of 'awesome' seems to require the use of so over other intensifiers such as very or really for the same reason I explained when I discussed example (7). Contrary to very and really, so belongs to the category of maximizers according to Quirk et al.'s classification (1973), which explains why so is the preferred intensifier to modify elements that carry intense semantic contents.

\subsection{Totally}

So has just replaced really in terms of frequency and my hypothesis is that it will be replaced sooner or later by another intensifier when its intensifying potential starts to wane. Although there is no way of predicting which intensifier will take its place, I suggest that totally may be a potential candidate insofar as it expresses maximal degree and its frequency of use is increasing among young speakers.

Consider the following examples:

(10) Barney: It's because you were totally, totally lame back then. HIMYM S03E16

(11) Ranjit: Don't hold back. This divider is totally soundproof. HIMYM S09E01

(12) Ted: Sorry, I totally got that wrong. HIMYM S03E17

(13) Robin (to Ted): You're always correcting people.

Marshall: You totally do that. HIMYM S03E308

In (10) and (11), totally reinforces the adjectives lame and soundproof to their maximum and therefore expresses the highest possible degree. In (12) and (13), interestingly, totally modifies the predicate which shows that its uses are expanding and that it is not restricted to the modification of adjectives. As I pointed out earlier, this may be seen as a sign that a process of grammaticalization has begun, even though it is not as advanced as it is for older intensifiers which are subjected to syntactic constraints. 
I have attempted to show that intensifying adverbs are constantly renewed when they are no longer felt to be expressive enough by analyzing the distributional context in which they occur. However, this does not seem to be sufficient to explain why and how intensifying adverbs that once were highly popular continue to be used in other contexts. I posit that there is a correlation between the intensifying force of adverbs (or the lack thereof), and the variations in register. In order to confirm this hypothesis, it is necessary to investigate criteria such as the situation in which these intensifiers are used, as well as the age/origin of the speakers who resort to those intensifiers. Such criteria will be discussed using examples from my corpus in the following and last subsection of this paper.

Variations in language registers

A closer look at the distributional context shows that the intensifiers under scrutiny are not used with the same types of adjectives, as the table below shows:

Table 2: Co-occurrence of very, really, so and totally with adjectives in the corpus

\begin{tabular}{|l|l|l|l|l|l|l|l|l|}
\hline \multicolumn{2}{|l}{ Very } & \multicolumn{2}{|l|}{ Really } & \multicolumn{2}{l|}{ So } & \multicolumn{2}{l|}{ Totally } \\
\hline 1 & Good & 16 & Good & 37 & Sorry & 112 & Cool & 8 \\
\hline 2 & Important & 14 & Nice & 22 & Glad & 38 & Fine & 7 \\
\hline 3 & Bad & 11 & Sorry & 17 & Good & 38 & Awesome & 6 \\
\hline 4 & Happy & 8 & Great & 16 & Bad & 36 & Different & 4 \\
\hline 5 & Nice & 8 & Hard & 15 & Hard & 35 & Hot & 4 \\
\hline 6 & Expensive & 7 & Bad & 12 & Sweet & 27 & Lame & 4 \\
\hline 7 & First & 7 & Long & 12 & Long & 26 & Rad & 3 \\
\hline 8 & Simple & 6 & Happy & 10 & Great & 25 & Right & 3 \\
\hline 9 & Sweet & 6 & Cute & 9 & Happy & 25 & New & 2 \\
\hline 10 & Close & 5 & Important & 9 & Excited & 23 & Okay & 2 \\
\hline 11 & Hot & 5 & Hot & 8 & Funny & 21 & Psyched & 2 \\
\hline 12 & Romantic & 5 & Sweet & 7 & Nice & 19 & Silent & 2 \\
\hline 13 & Special & 5 & Funny & 6 & Cool & 18 & Sweet & 2 \\
\hline 14 & Well & 5 & Stupid & 6 & Fast & 17 & True & 2 \\
\hline 15 & Attractive & 4 & Cool & 5 & Cute & 16 & Affectionate & 1 \\
\hline 16 & Big & 4 & Excited & 5 & Stupid & 15 & Amicable & 1 \\
\hline 17 & Hard & 4 & Weird & 5 & Awesome & 14 & Annoying & 1 \\
\hline
\end{tabular}




\begin{tabular}{|l|l|l|l|l|l|l|l|l|}
\hline 18 & Long & 4 & Big & 4 & Romantic & 12 & Disgusting & 1 \\
\hline 19 & Small & 4 & Crazy & 4 & Hot & 10 & Boring & 1 \\
\hline 20 & Casual & 3 & Creepy & 4 & Far & 9 & Calm & 1 \\
\hline
\end{tabular}

47 I selected the twenty adjectives that co-occurred most frequently with very, really, so and totally. I used bold characters to highlight adjectives that co-occur with all four intensifying adverbs and italics to highlight adjectives that only co-occur with so and totally.

The results show that even if very and really tend to modify adjectives denoting emotions or judgements (good, bad, nice, happy, sorry, etc.), those emotions or judgements appear to be rather moderate. Furthermore, those adjectives usually belong to the formal or standard registers while so and totally tend to co-occur with adjectives or other parts of speech belonging to colloquial language (cool, awesome, hot, lame, rad, psyched, etc.) and denoting more intense feelings or judgements. Consider the following examples:

(14) Robin: Oh, hey, Simon. Great show. You guys still rock.

Simon: Yeah. They totally dug my bass solo. Man! Why can't I always feel this alive?! HIMYM S03E16

(15) Marshall: Robin cancelled her date...

Ted: What? She was totally psyched for it like an hour ago. HIMYM S05E17

(16) Bob: Good to meet you. Sorry I'm late. I just got off the phone with my parents.

Ted: Parents?

Bob: They were totally on my case: "What are you gonna do with your life? You're forty-one." and I'm like, "Chillax, snowboarding is a legit career. You ought to be stoked I found my bliss." HIMYM S03E09

Examples (14) to (16) are particularly relevant to confirm my hypothesis of a correlation between the use of newly created intensifiers, their intensifying force and the age/origin of the speakers. In each example, I underlined lexical elements pertaining to informal language, which tends to confirm that totally is mostly used in informal contexts. In (14), Robin is invited to a rock concert and she meets her former high school boyfriend, a musician, on whom she still has a crush. In this particular scene, she behaves like a teenager and not like a grown woman. It is therefore not surprising to find evidence of her 'regression' in her speech. In example (16), the use of totally displays the same particularities. Bob is a 41-year-old man and yet he behaves and talks like a teenager. He resorts to abbreviations (legit), to the word formation process known as 'blending' (chill + (re)lax 䀭 chillax) and to the informal adjective 'stoked' defined as "completely and intensely enthusiastic, exhilarated" by the Urban Dictionary.

It is also worth noting that according to the table above, some adjectives (in bold) may be used with all four intensifiers. What is striking, when taking a closer look at the use of the adjective 'hot' for instance, is that its meaning will differ according to the intensifier that modifies it as the following examples show:

(17) Waitress: Careful. The plate is very hot. HYMYM S01E21

(18) Ted: You got me a hooker. A really hot hook - A hooker! HYMYM S01E19 
(19) Ted: Okay. No. See, look, that all sounds good, and we'll still be friends and move on, but... did he have to be so hot? The guy's an Adonis. HYMYM S03E01

(20) Barney: She's totally hot and really fun. HYMYM S03E04

51 In (17), hot is used to refer to the notion of 'heat' quite literally. In examples (18), (19) and (20) hot displays a shift in meaning. Indeed, it is used to refer to the degree of beauty of a person and this use is rather colloquial. While it would not be impossible to use very to modify hot when it refers to someone's beauty, it is not the case of the occurrences found in our corpus. Very is mostly used to modify hot when it itself modifies a noun belonging to standard language, while really, so and totally may collocate with a more colloquial use of hot.

This tends to support the idea that there is a correlation between the use of intensifiers and language registers as well as the idea that intensifiers that have lost their intensifying force over time through overuse are recycled to be used in more standard registers. The link between the type of intensifier used and the language register is therefore quite obvious and confirms the assumption I initially formulated.

\section{Conclusion}

The present study has shown that the renewal process of intensifiers does not merely involve the emergence of newer, fresher intensifiers and the disappearance of older intensifiers whose semantic content is no longer perceived as sufficiently expressive to remain the most popular intensifiers. The waning of the semantic contents of these intensifying adverbs is directly linked to the high frequency of use, which itself causes the loss of their intensifying force. The loss of expressivity leads to the recycling of intensifying adverbs. The formerly highly intense, popular adverbs do not merely cease to be used, but they are restricted to more formal contexts and therefore may occur in written speech while the newly created adverbs tend to be used in informal contexts by younger speakers who wish to affirm that they belong to a specific social group through the use of 'fashionable' expressions. When these expressions are used by other groups, their frequency of use increases, but at the same time they lose their intensifying force and their appeal to the younger speakers, who will create newer, fresher terms, which causes the cycle of the intensification treadmill to start all over again.

\section{BIBLIOGRAPHY}

BAUER Laurie \& BAUER Winifred, 2003, “Adjective booster in the English of young New

Zealanders", Journal of English Linguistics 30.3, 244-257.

BENZINGER Edith, 1971, Intensifiers in Current English, University of Florida.

BOLINGER Dwight, 1972, Degree Words, The Hague: Mouton de Gruyter. 
BORDET Lucile, 2014, «L'intensification en anglais : entre grammatical et lexical. Etude de corpus de la série américaine How I Met Your Mother », Les Amis du Crelingua, 5-22.

BORDET Lucile, 2014, L'intensification en anglais : entre grammatical et lexical, PhD dissertation, Université de Lyon (Jean Moulin - Lyon 3).

BORDET Lucile \& JAMET Denis, 2015, « Degré et intensification : essai de typologie », Anglophonia, http://anglophonia.revues.org/549 (30 janvier 2016)

BURRIDGE Kate \& BERGS Alexander, 2016, Understanding language change, London/New York: Routledge.

BRINTON Laurel J., 1996, Pragmatic Markers in English: Grammaticalization and Discourse Functions, Berlin/New York: Walter De Gruyter.

BRINTON Laurel J. \& TRAUGOTT Elizabeth C., 2006 (2005), Lexicalization and Language Change,

Cambridge: Cambridge University Press.

BULGIN James, ELFORD Nicole, HARDING Lindsay, HENLEY Bridget, POWER Suzanne \& WALTERS Crystal, 2008 , "So very really variable: social patterning of intensifier use by Newfoundlanders online", Linguistica Atlantica 29: 101-115.

BUSSMAN Hadumod, 1996, Routledge Dictionary of Language and Linguistics, London / New York, Routledge.

CLAUDI Ulrike, 2006, "Intensifiers of adjectives in German", Language Typology and Universals 59 (4), 350-369.

DEFOUR Tine, 2012, "The pragmaticalization of verily, truly and really. A corpus-based study on the developments of three truth-identifiying adverbs", in MARKUS M. \& HEUBERGER R. (eds.), Middle and Modern English Corpus Linguistics: A Multi-Dimensional Approach, Amsterdam/Philadelphia: John Benjamins, 75-92.

HERWIG Rolf, 1998, "Putting it mildly: the interrelation between adverbs of manner and adverbs of degree", Erfurt Electronic Studies in English, available at http://webdoc.sub.gwdg.de/edoc/ia/eese/ artic98/herwig/3_98.html

LABOV William, 1984, “Intensity”, in SCHRIFFIN D. (ed.), Meaning, Form and Use in Context: Linguistic Applications, Washington DC: Georgetown University Press, 43-70.

LOEWENBERG Ina, 1982, "Labels and hedges: the metalinguistic turn", Language and Style 15, 193-207.

LORENZ Gunther, 2002, "Really worthwhile or not really significant? A corpus-based approach to the delexicalization and grammaticalization of intensifiers in Modern English", in WISCHER I. \& Diewald G. (eds.), New Reflections on Grammaticalization, Amsterdam: John Benjamins, 143-161.

MÉNDEZ-NAYA Belén, 2008, "Special issue on English intensifiers", English Language and Linguistics 12 (2), Cambridge: Cambridge University Press, 213-219.

Merriam-Webster Dictionary of English Usage, 1994, Merriam-Webster Incorporated.

Merriam-Webster Unabridged, 2014, Online dictionary.

MUSTANojA Tauno F., 1960, A Middle English Syntax, Helsinki: Société néophilologique.

PARADIS Carita \& BERGMARK Nina, 2003, “'Am I really really mature or something?': really in teen talk", Gothenburg Studies in English 84, 71-86. 
PARTINGTON Alan, 1993, “Corpus evidence of language change: The case of intensifiers", in BAKER M. \& FRANCIS G. (eds.), Text and Technology: in Honour of John Sinclair, Amsterdam: John Benjamins, 177-192.

PINKER Steven, 2008, The Stuff of Thought: Language as a Window into Human Nature, London: Penguin.

QUIRK Randolph, et al., 1973, A Comprehensive Grammar of Contemporary English, New York: Hartcourt Brace Jovanovich.

Random House Webster's Unabridged Dictionary, 2005, Random House Reference.

RISSANEN Matti, 2008, "From 'quickly' to 'fairly': on the history of 'rather"', English Language and Linguistics 12 (2), 345-359.

RECSKI Leonardo Juliano, 2004, “'It's really ultimately very cruel': contrasting English Intensifier collocations across EFL writing and academic spoken discourse", Delta 20 (2), São Paulo Dec., 211-234.

STOFFEL Cornelis, 1901, Intensives and Down-toners, Heidelberg: Carl Winter.

TAGLIAMONTE Sali A. \& RoBerTs Chris, 2005, "So weird, so cool, so innovative: The use of intensifiers in the television series Friends", American Speech 80 (3), 280-300.

TAGLIAMONTE Sali A., 2007, “So different and pretty cool: Recycling intensifiers in Toronto, Canada", Special Issue of English Language and Linguistics, Intensifiers, 12 (2), 361-394.

TAGLIAMONTE Sali A. \& D'ARCY Alexandra, 2007, "Frequency and variation in the community grammar: Tracking a new change through the generations", Language Variation and Change 19 (2), 341-380.

TRAUGOTT Elizabeth C., 1995, "The role of the development of discourse markers in a theory of grammaticalization", http://www.stanford.edu/ traugott/papers/discourse.pdf XIAO Richard \& TAO Hongyin, 2007, “A corpus-based sociolinguistic study of amplifiers in British English”, Sociolinguistic studies 1.2, 241-273.

\section{NOTES}

1. Most frequently-used intensifiers are also considered as having undergone a grammaticalization process. I will not be discussing this particular point in this paper, but I argue that the development of intensifiers pertains to both a lexicalization process and a grammaticalization process, which are seen as complementary. See Bordet [2014] for a detailed explanation.

2. According to Tagliamonte \& Roberts [2005], the influential groups in the creation and spread of new intensifiers rank between the ages of 18 and 35 .

3. My emphasis.

4. According to Traugott [1995; 2012], the development of discourse markers is closely linked to the grammaticalization of adverbs. This phenomenon is referred to as pragmaticalization and involves a great deal of subjectivity. In a different study Bordet [2014], I have shown that intensifiers that have reached the most advanced stages of grammaticalization tend to undergo a pragmaticalization process and are used as discourse markers.

5. I used the scripts and corrected them manually when necessary. While it may be argued that the scripts do not take the oral dimension into account, it was a deliberate choice to leave the 
phonological dimension aside for this specific study, which concentrates on the semantics of intensifiers as well as on their distributional properties.

6. The slight decline of its use over the last three seasons may be explained by the fact that the characters have grown older. Indeed, most occurrences are found in the speech of younger speakers or speakers who wants to come across as young and trendy.

7. The various degrees of intensity I recognized are based on Quirk et al.'s [1973: 214-220] classification of intensifiers which can be divided into the following subcategories according to their semantics: emphasizers (definitely), maximizers (completely), boosters (very), compromizers ( kind of), diminishers (partly), minimizers (hardly) and approximators (almost).

8. It may also sound unnatural because "very great" is generally used to refer to the size of something.

9. So was obviously used before, even in Old English, but not as an intensifier. The use of so as an intensifier is thought to derive from the correlated structure so...that, in which the THAT proposition had been erased. See Bulgin et al. [2008] for further detail on the emergence of so.

10. So is in complementary distribution with such (a) which can only be used to modify attributive adjective. Let us remind the reader of the fact that such is etymologically linked to so since it is a combination of swa (so) + like. See Bordet [2014] for a detailed explanation.

\section{ABSTRACTS}

This paper investigates the renewal of intensifiers in English. Intensifiers are popularized because of their intensifying potential but through frequency of use they lose their force. That is when the renewal process occurs and promotes new adverbs to the rank of intensifiers. This has consequences on language register. "Older" intensifiers are not entirely replaced by fresher intensifiers. They remain in use, but are assigned new functions in different contexts. My assumption is that intensifiers that have recently emerged tend to bear on parts of speech belonging to colloquial language, while older intensifiers modify parts of speech belonging mostly to the standard or formal registers. There seems to be a correlation between the intensifying force of an adverb and language register.

Cet article étudie le renouvellement des intensifieurs en anglais. Ces derniers gagnent en popularité de par leur force intensificatrice intrinsèque mais ils perdent plus ou moins rapidement cette force à cause d'une fréquence d'utilisation relativement élevée. C'est à ce moment-là qu'intervient le phénomène de renouvellement qui va promouvoir de nouveaux adverbes au rang d'intensifieurs. Ceci a des conséquences sur le registre de langue. Les intensifieurs les plus «anciens» ne sont pas pour autant entièrement remplacés par de «nouveaux » intensifieurs considérés plus expressifs. Ils perdurent, mais se voient attribuer de nouvelles fonctions dans différents contextes. Le postulat autour duquel s'organise cet article est le suivant: les intensifieurs nouvellement créés tendent à modifier des éléments du discours appartenant au registre familier, tandis que les intensifieurs plus anciens tendent à modifier des éléments du discours relevant du registre standard ou soutenu. Une corrélation semble exister entre la force intensificatrice d'un adverbe et le registre de langue dans lequel celui-ci est employé. 
INDEX

Mots-clés: intensification, intensifieurs, renouvellement, registre de langue, lexicalisation

Keywords: intensification, renewal, lexicalization, intensifiers 